\title{
Research on Numerical Control Technology Teaching Reform Based on Virtual Reality Technology \\ DongFang $\mathrm{Hu}^{1, \mathrm{a}}$ and Zhuo Wang ${ }^{1, \mathrm{~b}}$
}

${ }^{1}$ School of Mechantronics Engineering, Henan University of Science and Technology, Luoyang 471003, China

ahdf@haust.edu.cn, ${ }^{b}$ wz_jd2013@163.com

Keyword: Virtual Reality Technology; Education and Reform; CNC Technology Teaching; Undergraduate Education; Practical Teaching

Abstract. In the context of outstanding engineer plan, a new type of education teaching reform idea based on virtual reality technology was proposed. This paper focuses on the discussion of virtual reality technology, especially the application in terms of numerical control technology curriculum reform as well as the reformation of CNC technology teaching, in order to enrich the teaching methods and improve the teaching efficiency or quality. The paper emphasizes the idea that the virtual reality technology is used to develop CNC system and utilizes the developed software in the practical teaching link, so that the students can be based on the system of a given virtual environment to solve practical problems, and improve the students' cognitive abilities.

\section{The Overview of Virtual Reality Technology}

The background and definition of virtual reality technology. Virtual reality technology (VR technology) is also called "Ling-jing" technology. This noun is derived from Lanier, the founder of America VPL Company, who puts forward a concept containing the basic characteristics of Immersion, interaction and imagination, and its essence is a kind of virtual system.

Basic composition for teaching NC technology in virtual reality system. The whole teaching NC technology of virtual reality system completes specific subdivision for virtual environment, a high performance processor, the display device as the core of the visual system, auditory system, and sound with the core of range sensors as the main azimuth position tracking device, together with the feedback system unit. The basic components in Fig. 1 are the teaching of NC technology in virtual reality system.

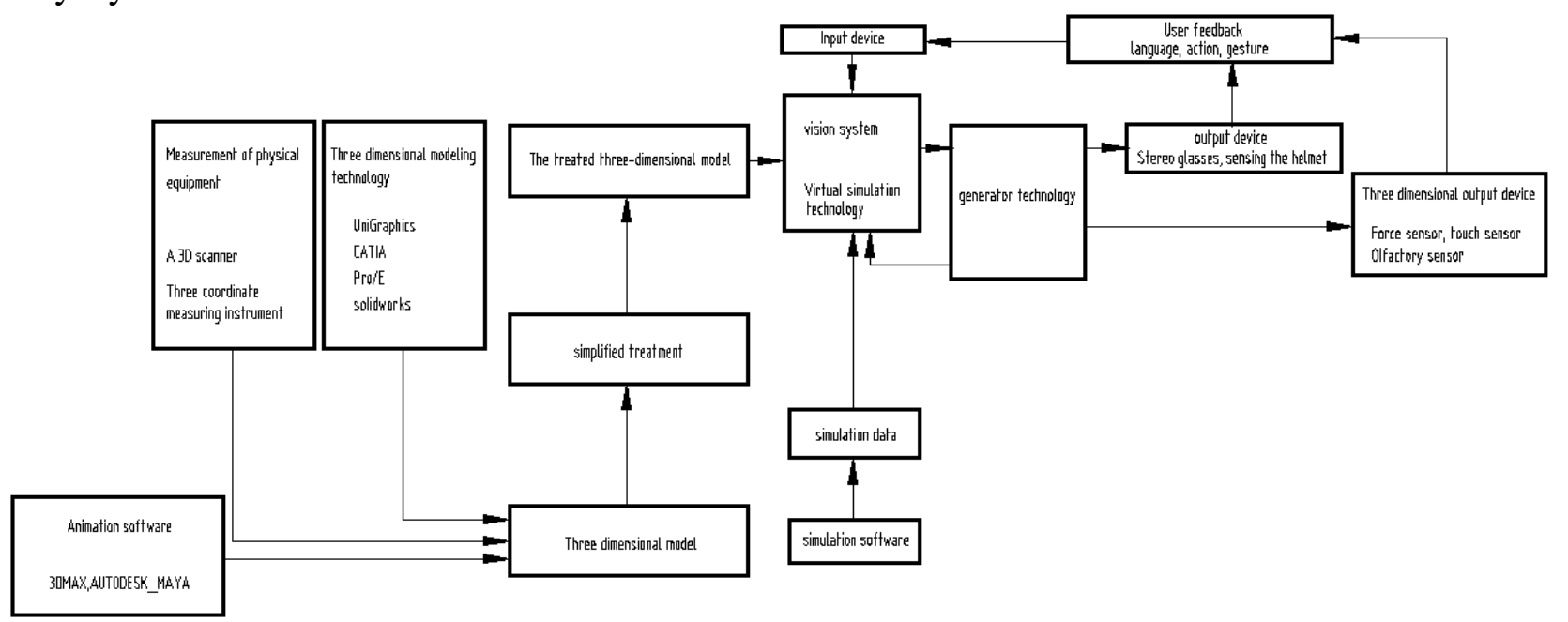

Fig. 1 The Teaching Type of Numerical Control Technology of Virtual Reality System 


\section{The Application of Virtual Reality Technology in NC Teaching Reform}

The current situation of NC technology teaching development. Since the twenty-first Century, a lot of modern media are widely used in teaching. The modern way of teaching does not depend on the books but the form of teaching. The introduction of 3D virtual reality technology remedies the deficiency of the NC technical courses.

The NC Teaching Platform Based on Virtual Reality Technology Education. With the development of virtual reality technology, the machining simulation system can simulate the real machining environment and working condition, it is an application of virtual reality technology in skill training NC simulation software. It can be divided into the four types:

(1) Desktop Virtual Reality

Desktop virtual reality (DVR) is the main image simulation at a personal computer and a low level of workstation. In the NC teaching, it enables students to use input devices - the computer screen to observe the virtual environment within the range of 360 degrees, students could manipulate the virtual device to simulate machining process.

(2) Immersive Virtual Reality

Immersive virtual reality provides teaching participants (students) a whole immersive experience, so that they have a kind of exposure to a virtual state of feeling. It mainly uses the helmet mounted display (HMD) and other equipment to make participants enclosing auditory and other sensory in a virtual reality theater (VR Theater) space. It utilizes the sound, the position tracker, data gloves and other manual input devices, in order to enable participants to produce a heart feeling on the scene.

(3) The augmented reality based on virtual reality

The augmented reality is a kind of technology, it will make the real environment and virtual reality scene together, which not only can reduce the generation of the complex experimental environment, and it is also easy to operate the virtual test environment object. The NC teaching application of augmented reality technology is usually carried out in the laboratory, but augmented reality technology can provide more benefits than other virtual reality technology.

(4) The distributed virtual reality

Distributed virtual reality system owns more geographically independent users (often called the host computer), which will be real-time connected through the computer network. These hosts share a common virtual space. In the virtual classroom, to solve bandwidth usual method, the local client in host CPU or GPU is used to complete the real-time calculation of virtual scene rendering required. Both of the mobile virtual characters and real instruments, mutual interaction parameter information are realized by network transmission.

The virtual reality technology course in practical application of NC subjects. According to the feedback information from some key colleges, researchers think that there are broad prospects for the technology of virtual reality; the following points should be the focus of reform:

First, putting up "the development and application of virtual reality technology" courses into the science and engineering undergraduate education, and its content mainly involves the VRML program technology, virtual reality scene environment shape design, animation and interactive function, the script node and Internet related content.

Second, for the interactive teaching innovation development, $\mathrm{CNC}$ teaching experiment is about the traditional described by the virtual teaching system by using Pro/E, UG_NX, VRML and JavaScript technology, in order to enable students to understand the general process and develop a mechanical product. The teacher guides students to use the UG_NX or Pro/E design software, completes the modeling and assembly of three-dimensional industrial products, then builds a platform based on the VRML program design teaching, and realizes the key animation through time sensing VRML (Time sensor), interpolation (Interpolator) and routing (ROUTE), acquire the assembly of parts information in virtual reality by using Anchor nodes, and finally changes the viewpoint of nodes . 


\section{Construction on the Training NC Machining Center based on Virtual Reality Technology}

When applying the computer simulation technology to the engineering training center, the most important thing is to avoid 40 or 50 people taking turns to operate only four or five equipment, and effectively improve the training time to every student, so that one person operates, a few people watch the situation, this will be more beneficial to the teaching goal. The training NC machining center based on virtual reality technology is shown in Fig. 2.

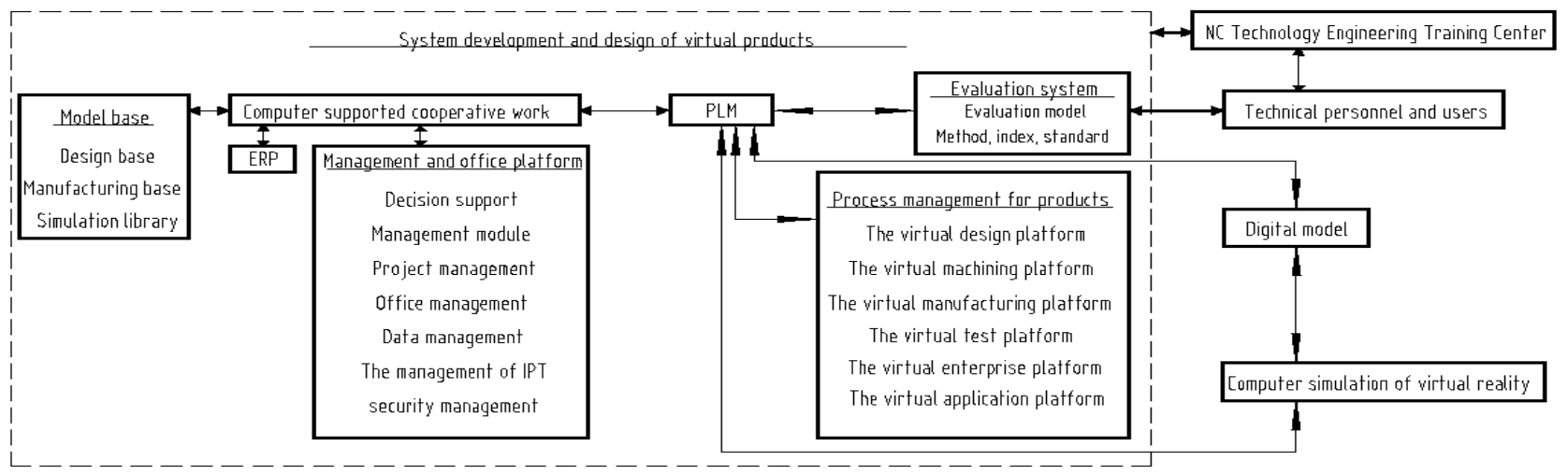

Fig. 2 The Training NC Machining Center based on Virtual Reality Technology

CNC Machining Training Center of virtual reality technology based on working principle is shown as above, technical staff and users (teachers and students) are simplified and the design of the actual product or product is comprehensively summarized. They use the virtual reality technology to complete the computer simulation and digital prototype of $\mathrm{NC}$ machining product. Users use the product evaluation system to evaluate the digital prototype. According to the evolutional results, users adjust the digital prototype constantly until the abstraction and synthesized digital prototype meets a specific requirement. The virtual design platform will make a virtual machining platform for the collaboration of the 5 platforms for CNC product specific design, digital prototype into the virtual design platform for virtual design. To guide the students in the virtual design, it is necessary to fully consider the follow-up support information, such as virtual processing platform, virtual manufacturing platform, virtual test platform and virtual platform etc., and complete the output to the virtual machining simulation analysis (including mechanics, thermodynamics, kinematics, dynamics, electromagnetic compatibility analysis), process planning, virtual manufacturing, virtual assembly and processing (including performance analysis, cost estimation, man hour estimate etc.). Virtual machining platform outputs the information feedback virtual design platform to modify the virtual design of the product. Virtual manufacturing platform optimizes the digital model of product layout design, equipment and environment integration, production planning and scheduling, feasibility analysis. At the same time, the information feed back to the virtual design platform and virtual processing platform, correcting the corresponding output of the two platforms. The virtual test platform and virtual platform receive the digital model of the process output and make virtual test. The design information feed back to the upstream process for improving designing or manufacturing products. When the digital prototype adopts the virtual design platform, virtual processing platform, virtual manufacturing platform, virtual testing platform and a virtual platform for using parallel optimization design to realize the final product digital model output. Meanwhile, the data transmission and share for virtual product between development and design of the system and engineering training center is using the computer supported cooperative work in network environment. ERP, virtual product model base, knowledge base design, manufacturing knowledge base and knowledge base provide a variety of resources and data for this system.

\section{The Reflection on the Teaching Practice of Domestic Key Universities}

Although much knowledge of virtual realities comes from different academic fields, but its core idea is suitable for the teaching reform of numerical control course. Furthermore, the curriculum 
inspires students to pay attention to concerned issues at home and abroad, especially showing solicitude for the mainstream equipment, the current development tools and platform cognitive. This teaching idea is enable students to understand the importance of this technology during their future development.

\section{Conclusions}

The college educational workers require researchers to focus on the following three aspects:

(1) Focus on the application of virtual reality technology, so that the students can compare the virtual environment with the real comparison.

(2) Connect with the numerical control technology course such as the computer graphics, multimedia technology, image processing technology and other courses, and teachers master the continuity of teaching, which makes the virtual reality technology effectively utilize in learning to stimulate students' innovation.

(3) Make full use of the virtual reality technology and the State Key Laboratory of ministry or province level research environment (software and hardware resources), and further strengthen the practice of numerical control technology curriculum.

It is believed that, in the future, the virtual reality technology will get more extensive development in the teaching reform of numerical control education.

\section{Acknowledgements}

The authors gratefully acknowledge the Project for education and teaching reform of Henan university of science and technology(No. 2012N-007) and the national superior course and billigual teaching demonstration course for financial support of this research work.

\section{References}

[1] Zeng Jianchao, Yu Zhihe. Virtual reality technology and its application[M]. Tsinghua University press, 1996.

[2] Song Da. Application and Design of Virtual Reality For Education[D].Northeast normal university,2005.

[3] Zuo Jianmin. The Study on Enforcing Route of "The Outstanding Plan" Based on the Angle of University-Enterprise Collaboration [J]. China Higher Education Research, 2014(2):70-73.

[4] Wang Yuerong. On the Application of Virtual Reality technology in teaching[J]. Wuxian hulian keji, 2013(11):73-76.

[5] Li Ye. The Virtual Realistic Technique is in the Teaching of Applied [J]. Information Security and Technology: 2013,4(7):84-85.

[6] Yang Guang, Lian Weiping, Guo Jingfeng. Commercial ride-on lawn mowing vehicle large frame dynamic characteristics and the structure optimization[J]. Journal of Jimei University, 2008,9(3):92-95.

[7] Wang Chenchen. The Application of Virtual Reality Technique in Library[J]. Research on Library Science, 2011(10):34-37.

[8] Lu Yingjun. The Application of Virtual Reality Technique in Digital Library[D]. Wuhan University,2013.

[9] Tian Yang, Dong Na, etc. Application of virtual reality technology in English teaching[J]. Electronic Test, 2014(18):141-143. 
[10] Liu Guiwen. Based on virtual reality technology PE teaching mode[J]. Electronic Test, 2014(18):63-65. 